\title{
La construcción de género en el Corbacho de Alfonso Martínez de Toledo
}

\section{The Construction of Gender in Corbacho by Alfonso Martínez de Toledo}

\author{
Roque Sampedro López \\ Universidad de Santiago de Compostela \\ https://orcid.org/0000-0001-8369-9635 \\ roque.sampedro.lopez@usc.es
}

Recibido: 30/04/2020; Revisado: 24/08/2020; Aceptado: 22/10/2020

\begin{abstract}
Resumen
El Corbacho es un texto castellano del siglo xv que gira en torno a la crítica y denuncia del llamado amor mundano. En el presente artículo se busca analizar el Corbacho de Alfonso Martínez de Toledo, escrito en Castilla hacia 1438, a través de una serie de conceptos extraídos de la historia de género. Para ello, tras estudiar brevemente el contexto y la autoría del Corbacho, se profundizará en el propio concepto de género y su relación con el discurso que presenta el texto. A continuación, se analizará la construcción de masculinidades hegemónicas y subordinadas y, finalmente, la configuración de distintas feminidades.
\end{abstract}

Palabras clave: Corbacho. Arcipreste de Talavera. Género. Castilla bajomedieval. Masculinidades. Feminidades.

\begin{abstract}
Corbacho is a fifteenth century Castilian text revolving around the criticism and denunciation of so-called worldly love. Using concepts from gender history, the purpose of this article is to analyse Corbacho, written by Alfonso Martínez de Toledo in Castile around 1438. Thus, after briefly outlining the context and authorship of the Corbacho, the very concept of gender and its relationship to the discourse of the text are examined. The article then analyses the construction of hegemonic and subordinate masculinities, before finally turning to the configuration of several femininities.
\end{abstract}

Key words: Corbacho, Archpriest of Talavera, Gender, Late Medieval Castile, Masculinities, Feminities. 


\section{INTRODUCCIÓN}

El propósito de este artículo es aplicar un conjunto de ideas extraídas, fundamentalmente, de la historia de género al Corbacho, ${ }^{1}$ un texto escrito por Alfonso Martínez de Toledo, Arcipreste de Talavera, en 1438, en el que elementos como lo masculino y lo femenino, las relaciones entre los sexos, el cuerpo, u otras cuestiones relacionadas con el género, tienen una gran relevancia. La obra, normalmente clasificada como misógina, es una suerte de crítica de la sociedad en la que vive el autor, la Castilla del siglo XV, en particular, a los ambientes de la corte de Juan II (1406-1454). Tomando como fundamento la idea de que la sociedad se encuentra en un momento de decadencia, Martínez de Toledo argumenta que el amor al mundo, es decir, el pecado, es el origen de dicho declive. Así, el amor mundano o amor desordenado, y las prácticas asociadas a este, traerían consigo una serie de consecuencias morales, sociales y espirituales de carácter perjudicial. Ahora bien, dentro del amor mundano, el Arcipreste se fija especialmente en las prácticas sexuales, detallando lo que él considera que son sus graves consecuencias. Además, se incluye también una lista de los vicios característicos de mujeres y hombres, en especial de las primeras. $Y$, frente al vicio y al amor al mundo, se opone el amor a Dios, que sería el origen de la virtud y la razón, y la realidad a la que hay que aspirar.

Estos elementos configuran un discurso de género, es decir, un sistema de representaciones sobre lo masculino y lo femenino, las normas que son propias para cada sexo, las maneras correctas de relacionarse, o diferentes formas de identidad masculina o femenina, en este caso en la Castilla del siglo Xv. En este sentido, para la intepretación de dicho discurso del Corbacho utilizaremos una serie de herramientas analíticas de la historia de género. Esto supondrá emplear la definición de género de Joan W. ScotT (1999), que lo entiende como una construcción social entorno a las diferencias percibidas entre los sexos. Además de a la obra de Joan Sсотт, también recurriremos a ideas y conceptos como los de masculinidades hegemónicas y subordinadas, o al de cultura de las mujeres, entre otros.

Así, con el propósito de entender cómo funciona el discurso sobre el género en el Corbacho, trataremos, en primer lugar, la autoría de la obra, la estructura del texto y el contexto en el que se ubica. Es decir, veremos algunos elementos de la vida y situación social de Martínez de Toledo, las intenciones del texto, sus motivaciones y sus consecuencias, en relación a la llamada querella de las mujeres. En segundo lugar, profundizaremos en la definición de género y analizaremos sus principales elementos en el Corbacho, esto es, los símbolos sobre lo masculino y lo femenino, la representación de instituciones que regulan las relaciones entre hombres y mujeres o la importancia del cuerpo. En tercer lugar, se estudiará la construcción de masculinidades hegemónicas, subordinadas y marginalizadas, prestando especial atención a la figura del amante cortés. Finalmente, se analizará lo femenino en el Corbacho, destacando la configuración de feminidades positivas y negativas en el discurso del Arcipreste.

1 El título de Corbacho para el texto no es el que pretendía el autor, que deja la obra sin titular. En general, la crítica ha aceptado que los contemporáneos de la obra la llamaban así en relación a Il Corbaccio de Bocaccio, de similar temática anti-femenina. Ahora bien, Ryan GILEs (2008) ha argumentado que también es posible que este nombre venga dado más bien debido a la figura del cuervo en la obra de Ovidio. 


\section{AUTORÍA, TEXTO Y CONTEXTO}

Resulta relevante, antes de abordar los elementos específicos del discurso de género que presenta la obra de Martínez de Toledo, analizar algunos de los fenómenos que rodean la construcción de dicho discurso. En este sentido, parece que hay al menos tres cuestiones relevantes. En primer lugar, la cuestión de la autoría, es decir, todos aquellos elementos que condicionan a la figura del Arcipreste de Talavera como autor que emite un discurso determinado, en este caso en relación al género. Nos referimos a características del personaje como su situación social, educación, relaciones institucionales, o incluso posibles vivencias personales, siempre en relación a los elementos de género que pululan en el Corbacho. En segundo lugar, el propio texto en sí. Las representaciones de lo masculino se dan en relación a todo un relato en el que destacan cuestiones como la oposición entre amor a Dios y amor al mundo, una estructura del texto determinada, unas fuentes particulares (homiléticas, escolásticas, médicas) y unas intenciones. Finalmente, el propio contexto en el que se sitúa la obra, caracterizado por una suerte de proliferación de discursos sobre la mujer, tanto desde géneros más líricos, como la poesía de cancionero, como a partir de tratados «antifemeninos» y «profemeninos». ${ }^{2}$ El Corbacho se identifica como uno de los primeros, dentro de todo un debate conocido como la querella de las mujeres.

Aunque no se sabe mucho de la vida de Alfonso Martínez de Toledo (nacido en Toledo hacia 1398), sí hay una serie de rasgos que ayudan a construir la autoría. Por una parte su título, Arcipreste de Talavera, junto con una actividad importante en asuntos eclesiásticos desde las primeras décadas del siglo XV, lo que nos lleva a pensar el autor como un miembro de la Iglesia, con una serie de responsabilidades en una institución que tenía como uno de sus roles fundamentales la producción de discursos normativos de carácter religioso. Esta normatividad afecta, obviamente, al área de la sexualidad y a las relaciones de género. Así, Martínez de Toledo se configura como un autor con una serie de relaciones institucionales e ideológicas, como un transmisor de los discursos eclesiásticos. En relación a esto último, otra cuestión fundamental es que se trata de un autor con formación universitaria: él mismos nos dice que es «bachiller en decretos» (BERMEJo, 1976). Así, no resulta sorprendente que durante todo el texto del Corbacho se manejen un amplio abanico de fuentes, desde elementos de derecho canónico, a textos de amor cortés como el de Andrea Capellanus, pasando por un vocabulario escolástico, teólogos como san Agustín, textos médicos, o autores más cercanos temporalmente al Arcipreste como Boccaccio. Tenemos, entonces, a un autor culto y formado. Finalmente podemos destacar uno de sus cargos, el de capellán del rey. Como capellán, Martínez de Toledo tendría un rol en la formación religiosa del rey y de la Corte, ${ }^{3}$ lo que nos lleva a situarlo como, posiblemente, un buen conocedor de

2 El Corbacho ha sido clasificado habitualmente como un texto misógino, pero este término parece llevar aparejado cierto anacronismo, además de no tener mucho valor analítico. La definición de Howard BLoch (1991: 5-6) de misoginia, que sería cualquier acto del habla que reduzca a la mujer a una categoría, me parece demasiado inespecífica para la Edad Media, ya que implicaría catalogar prácticamente todos los textos sobre lo femenino bajo el concepto de misoginia, y esta falta de distinciones resta valor analítico al término. Además, la clasificación de textos en una dicotomía misóginos/profemeninos puede llevar a ocultar los matices y múltiples sentidos que puede tener un discurso determinado. Así, SERRANO (2016: 66-67) afirma que la diferenciación en el Corbacho entre buenas y malas mujeres rebajaría el grado de misoginia de la obra.

3 A todo esto habría que incluir el rol que parece desempeñar Martínez de Toledo en las festividades del Corpus Christi en Toledo, en relación a actividades teatrales (VélEz-SAINZ, 2013: 118-122). Esto, 
los ambientes cortesanos y los discursos que allí circulaban, como los propios del amor cortés. Así, como veremos, es posible pensar el Corbacho como un texto con el que se busca alejar a los jóvenes cortesanos de tentaciones sexuales a través de un discurso peyorativo hacia la mujer (MAÑERO, 1992).

Continuando en el nivel de la autoría, hay otro elemento de interés. Se trata de la posibilidad de que Martínez de Toledo tuviera una amante, desde los años veinte del siglo $\mathrm{xV}$, cuando es denunciado por otro eclesiástico por vivir en concubinato (GERLI, 1984: 15-19 y 49-50). Un elemento así añadiría una capa de complejidad a la figura del Arcipreste y su relación con la obra, que bien podría funcionar como una manera de intentar limpiar su nombre, o bien como una proyección de sus propias contradicciones internas a todas las figuras masculinas que pueblan el texto, y que son criticadas por mantener relaciones sexuales fuera del matrimonio.

En lo tocante al texto, escrito hacia 1438, es interesante situar todo el discurso sobre lo masculino y lo femenino en una obra cuyo eje fundamental es la oposición entre el amor a Dios y el amor al mundo, ${ }^{4}$ junto con otras oposiciones como el pecado y la virtud, la salvación y la condena o la razón y las pasiones (MAÑERO, 1997: 59-60). Partiendo de esta idea nuclear, el Corbacho, a través de sus cuatro partes trata una gran cantidad de temas, dando siempre un lugar central a la sexualidad «desordenada». Así, la primera parte, muy influida por el texto De amore, de Andreas Capellanus, ${ }^{5}$ se dedica a describir las consecuencias del «amor desordenado» a nivel personal, moral, corporal, social y espiritual. La segunda parte resulta ser una crítica a las «malas mujeres» y sus vicios: la avaricia, la vanidad, la falta de constancia, el engaño, etc. La tercera, en cambio, se dedica a los varones, aplicando la teoría de los humores propia de la medicina medieval. Finalmente, la última parte es una defensa del libre albedrío frente a toda una serie de perspectivas deterministas de corte astrológico.

Además, resulta interesante reflexionar sobre las intenciones del autor y como estas afectan a la posible interpretación del texto. Así, podemos pensar el texto no como una crítica en general a las mujeres y al sexo, sino más bien como un texto de carácter moralizante y didáctico dedicado a una audiencia determinada: los jóvenes cortesanos. En el prólogo, el autor afirma: «algunos que no han follado el mundo ni han bevido sus amargos brevages ni han gustado de sus viandas amargas, que para los que saben y han visto, sentido y hoído non lo escrivo nin digo, que su saber les abasta para se defender de las cosas contrarias» (GERLI, 2011: 62). Además, se ha venido destacando que la obra sigue una serie de procedimientos que se podrían describir como terapeúticos. La denigración de las mujeres, el uso de elementos grotescos o la inserción de relatos, descripciones o interyecciones que advierten sobre el peligro del «amor desordenado» encajarían

unido a la estructura homilética del texto (GERLI, 1975) y a las dimensiones performativas del mismo (SANMARTín BASTIDA, 2003a), ahonda en la dimensión del autor como transmisor de ideas y generador de representaciones, especialmente en relación a los jóvenes cortesanos. Para el papel de la Corte como institución hegemónica en la producción de discursos y representaciones en la Edad Media, véase Le Goff (1974: 87-88). Hervé MARTIN (1996: 11-16) discute en términos generales los centros de producción ideológica en la Edad Media.

4 En este sentido, se perciben influencias de la sermonística medieval, uno de los temas que se han destacado en el estudio del Corbacho. Véanse GerLi (1975), DiFranco (1982) y GonZÁlez-CaSASNOvas (1991). 5 La obra también incluiría como fuentes a San Agustín, Boccaccio o Francesc Eiximenis. Véanse GerLI (1978), WISE (1980) Y ARCHER (2005: 64-74). 
dentro de un pensamiento médico que concibe el amor como una enfermedad con una suerte de tratamiento psicológico, a través de representaciones que provoquen una suerte de rechazo emocional a las mujeres y al sexo. ${ }^{6}$

Teniendo en cuenta estos elementos, podemos encajar el texto en un contexto cultural determinado, la Castilla de Juan II, en la que, a nivel literario, existe una importante presencia del «amor cortés». Caracterizado prácticamente como una doctrina moral y una normatividad en torno a las relaciones de género, este tipo de literatura destacaría a la mujer como una suerte de figura inalcanzable, que llevaría al hombre a la virtud, adaptando elementos cristianos para construír una suerte de «religión del amor». Así, poetas como Juan Rodríguez de Padrón escriben textos como «Diez mandamientos del amor», una clara alusión al Decálogo bíblico (GERLI, 1981: 67-70, 74 y 79-81). Gran parte del Corbacho es una crítica a la concepción del amor en los ambientes cortesanos, en la que se arremete contra elementos fundamentales de esta literatura, parodiando a los amantes corteses, denigrando a las mujeres y la preocupación por el aspecto o describiendo los efectos negativos de las prácticas sexuales alabadas por los poetas corteses.

Así, el Corbacho forma parte de un contexto de crisis en los discursos sobre el género, un contexto en el que existen visiones conflictivas acerca de las representaciones de la feminidad y la masculinidad, sobre las normas que deben regular las relaciones entre los sexos, o incluso sobre la concepción del cuerpo. En definitiva se trata de un conflicto sociocultural que se plasma en el nivel de las representaciones. ${ }^{7}$ La obra de Martínez de Toledo provoca una serie de contestaciones por parte de autores relacionados con la corte, escritores que también habrían participado en la poesía cortés. Se conforma lo que se ha denominado como querella de las mujeres, ${ }^{8}$ un debate en torno a las concepciones de lo masculino y lo femenino, en el que Juan Rodríguez de Padrón, Diego de Valera y Álvaro de Luna, principalmente, responden a los argumentos del Arcipreste de Talavera, tachándolo de «difamador», y alabando lo femenino y las figuras femeninas. ${ }^{9}$ Elementos como las virtudes de las mujeres, las mujeres

\footnotetext{
6 Sobre los aspectos terapeúticos del discurso antifemenino véanse SOLOMON (1997), ArCHER (2012) y SEIDENSPINNER-NÚNEZ (1997).

7Además, siguiendo algunos de los presupuestos de la nueva historia cultural podemos suponer que este conflicto entre representaciones es también un conflicto entre grupos sociales, especialmente entre parte del clero y la corte. En relación a la nueva historia cultural y sus elementos teóricos véase CHARTIER (1999), y de manera más general SENRA y PONS (2005).

8 Sobre la querella de las mujeres en general véanse Kelly (1982), ZIMMERMANN (1999) y RivERA GARREtas (1996). Para el caso castellano Vargas Martínez (2000; 2013), Fuentes Pérez (2009), Serrano (2012) y SAMPEdro (2018). Asimismo, puede consultarse el texto de Bolufer y CABré (2015) para un conjunto de reflexiones sobre la querella en España entre 1400 y 1800. Para una inclusión de Alonso de Cartagena en el debate castellano, véase Ríos DE LA LLAVE (2018).

9 El texto del Arcipreste se escribe en 1438, mientras que los de Juan Rodríguez del Padrón, Diego de Valera y Álvaro de Luna en 1444, 1445 y 1446 respectivamente, lo que parece indicar una cierta conexión, si bien es posible que Il Corbaccio (c. 1355) de Boccaccio se otro de los objetivos de las críticas de los autores cortesanos. Ahora bien Vélez-SAínz (2006: 267-268) ha argumentado que el Triunfo de las donas de Juan Rodríguez del Padrón sea una contestación a la obra de Martínez de Toledo, y también a documentado la oposición contra Álvaro de Luna por parte del autor del Corbacho (VÉLEZ-SAínZ, 2013: 122 y ss). Este autor (2013: 212), además, interpreta toda la cuestión de la querella como una serie de tomas de posición en relación a las costumbres cortesanas. Así, «la corte de Juan II sirvió como un locus de aprendizaje de costumbres corteses que cristalizaron en la producción de una serie de textos de carácter filógino y autocelebratorio o misógino y satírico en los que tanto la defensa como el ataque a la mujer indicaba e implicaba necesariamente una defensa o un ataque a los valores cortesanos y
} 
míticas, bíblicas o históricas de gran valía o la interpretación de relatos como el de la Caída, cobran una importancia fundamental en las discusión sobre lo femenino y, paralelamente, también lo masculino. Estamos hablando, por lo tanto, de un momento de crisis en las formas de entender las diferencias sexuales, una querella en la que el discurso de género que presenta el Corbacho tiene una especial relevancia, al ser el texto que desencadena el debate. ${ }^{10}$

A la hora de estudiar el discurso de género en el Corbacho, contamos, entonces, con tres aspectos paralelos a las representaciones sobre las diferencias entre los sexos (autor-autoría, texto, y contexto) que sirven de soporte a la hora de interpretar elementos como lo masculino y lo femenino, las instituciones que regulan las relaciones de género, o la cultura femenina. El autor, de corte eclesiástico, nos permite situar el discurso del texto en una tradición eclesiástica de pensamiento sobre la mujer, además de permitirnos reflexionar sobre las intenciones del texto, en relación a las adscripciones institucionales del autor como capellán del rey. A mayores, la tónica general del texto, es decir, la oposición entre amor a Dios y amor al mundo sirven como base para entender como se construyen las masculinidades y feminidades, tanto a nivel positivo como negativo. Finalmente, el contexto cultural de la obra (el amor cortés) y sus consecuencias (la querella de las mujeres) nos permiten situar los discursos del Arcipreste en un momento de redefinición de lo masculino y lo femenino.

\section{EL GÉNERO Y SUS ELEMENTOS EN EL CORBACHO}

El tema principal del Corbacho, la oposición entre el amor mundano y el amor a Dios tiene, a nivel social, una lectura relacionada con un tipo de relaciones particulares, las relaciones de género. La principal preocupación social del Arcipreste son las relaciones entre hombres y mujeres, las normas que deben regular dichas relaciones, los comportamientos y roles sociales apropiados de ambos sexos, y las consecuencias de las diferentes formas de relación entre ambos sexos, de acuerdo con el marco interpretativo con el que trabaja. En definitiva, se trata de una preocupación sobre el género, sobre los aspectos relativos a lo masculino y lo femenino que no están inmediatamente determinados por el sustrato biológico, y por tanto, son una construcción social y cultural, una realidad históricamente cambiante (MorANT, 2000: 294-295). ${ }^{11}$ Al tratar el Corbacho, entendiendo el texto como un conjunto de representaciones sobre hombres y mujeres, estamos abordando uno de los aspectos del género que se dan en la sociedad medieval. Hablamos de un discurso con una serie de dinámicas específicas, entre las que se pueden destacar la construcción de identidades y roles, la expresión de poder, la

caballerescos que los produjeron». En este sentido, argumentaremos más abajo que la construcción de las masculinidades en el Corbacho supone una crítica a los amantes cortesanos.

10 Con todo, se ha interpretado a menudo que el debate tiene un importante carácter retórico. Al repespecto, Julian WeIss (2002: 244), partiendo de la obra de BouRdiEU, a afirmado respecto del debate: «Certainly, it can be viewed as a game (...), but it was one played seriously and with serious consequences. The composition of poetry was part of the cut and thrust of courtly life, with its constant struggle over rank and status». Y el estatus se discutia y contestaba, al menos en parte, en relación a las construcciones de la masculinidad y la feminidad. En este sentido, J. WeIss (2002: 250) destaca como para autores como Diego de Valera, Juan Rodríguez del Padrón o Álvaro de Luna la masculinidad cortesana se definía a través de la demostración de cierta maestría intelectual.

11 Sobre la historia de género en la Edad Media, véanse ElLIOTt (2008) y JeAnNe (2008). 
reproducción de reglas y normas de comportamiento social o las instituciones. Así, las representaciones del Corbacho, en cuanto discurso sobre las relaciones entre hombres y mujeres, tienen una dinámica específica. De esta forma, son susceptibles de ser analizadas en relación con las diferentes identidades que se construyen, a cómo se expresa el poder, o a otros elementos específicos del género.

Historiográficamente, el concepto de género es el núcleo fundamental de la llamada historia de género, tendencia historiográfica que surge a partir de los años 80, preguntándose sobre la construcción de lo masculino y lo femenino como fenómenos contingentes y los diferentes modos en los que el poder está implicado en las relaciones entre hombres y mujeres. En este sentido, el artículo de Joan ScotT, «Gender: a useful category of historical analysis», publicado en 1986, resulta seminal, ya que en él se realiza un aclarado teórico, así como una reflexión conceptual en la que se aboga por el uso del "género» como una categoría muy adecuada para el análisis histórico. A partir de estas ideas, es posible construir un marco analítico para el estudio del género en el Corbacho.

En primer lugar, entendemos el género como una construcción social, es decir como un conjunto de reglas que en determinadas situaciones sociales indican cómo se deben comportar hombres y mujeres en relación con su sexo, así como las formas en las que un grupo social interpreta, evalúa y representa las relaciones entre hombres y mujeres (WEST y ZIMMERMANN, 1987: 125-127). Es decir, el género implica tanto una serie de formas de relacionarse en sociedad como los discursos que dan sentido a dichos comportamientos. Resulta importante también, diferenciar entre sexo y género. El sexo son las realidades biológicas (reproductivas, anatómicas, genéticas) que diferencias a hombres y mujeres y que pueden influir en las relaciones sociales, mientras que el género son las formas en las que se significan dichas diferencias tanto en el discurso como en la acción. ${ }^{12}$

En segundo lugar, las diferencias sociales que vienen dadas de las distintas concepciones de lo masculino y lo femenino dan lugar a la existencia de relaciones de poder, tanto entre los sexos como entre hombres y entre mujeres. Que existan diversas formas de actuar, es decir, distintos roles, provoca que haya diferencias en el acceso a recursos materiales y simbólicos, como el estatus o la reputación, o incluso el valor moral y ético de una persona. Estas distinciones se plasman, y reproducen, a través de discursos como el del Corbacho, en los que se valoran comportamientos, formas de relacionarse sexualmente, $u$ otros fenómenos sociales, de acuerdo con su adecuación a varios ideales (principalmente la santidad, así como la posibilidad de salvarse o condenarse).

En este sentido, a la hora de analizar la articulación de las diferencias entre lo masculino y lo femenino en el Corbacho, recurriremos a las ideas de J. ScOTT (1999: 42-44), para quien el género, en cuanto forma de organizar la sociedad en relación con el dimorfismo sexual, está compuesto de cuatro elementos diferenciados: símbolos, normas, instituciones e identidades. En el texto de Martínez de Toledo todos estos elementos relativos a lo masculino y a lo femenino se articulan en relación con otras dicotomías -amor divino/amor mundano, razón/emociones, virtud/vicio-, pero no necesariamente de una forma directa. Es decir, lo masculino y lo femenino se construye de una forma compleja y no cabe identificar

12 Sobre el concepto de género y la historia, véanse Boydston (2008), Bock (1991), MeYerowitz (2008), CANNing (2006: 3-26) y Hernández SANDOICA (2004: 437-471). Además véase SANTANA-Pérez y SANMARTín BARros (2020: 354-355) para una contextualización de la historia de género dentro de las nuevas corrientes historiográficas de los últimos treinta años. 
necesariamente al hombre con el amor divino y la razón y a la mujer con el amor mundano y las emociones, por ejemplo.

a) Símbolos: la masculinidad y la feminidad se construyen en relación con un conjunto de símbolos culturales que pueden asocian determinadas realidades -actuales o imaginadas- al varón y a la mujer, normalmente en relación con valores morales. Así, en el Corbacho tenemos personajes ejemplares mediante los cuales se indican comportamientos apropiados o inapropiados, como pueda ser la advocación a la Virgen en el prólogo, pero también en otras ocasiones, asociada siempre a la intercesión para la salvación de las almas (GERLI, 2011: 88, 139, 201), lo que muestra, aunque sea de forma soslayada, la asociación de cierta feminidad con la salvación y con el amor a Dios. Sin embargo, la presencia de símbolos femeninos tiende hacia figuras asociadas a la perdición -espiritual o social- y el pecado. Es el caso de Betsabé, Helena de Troya, o Eva (GerLI, 2011: 101-102, 182 y 201). De forma interesante, se contraponen las figuras de Eva y Adán con la Virgen y Cristo:

Por ende, amigos, todo loco amor, pompa e vangloria nos lançemos, e en tal manera nos avemos que de aquel verdadero Sidrach, Ihu Xpo, fijo de la humil, graçiosa abogada nuestra la Virgen Santa María, seamos amados [...] por el derramamiento de la su propia sangre que [...] por nos en el árbol de la Vera Cruz derramó, por nos redemir e salvar del pecado a que nuestro padre Adam con nuestra madre Eva nos obligaron e sometieron (GERLI, 2011: 201).

Con este tipo de relatos el Arcipreste recurre a una serie de personajes que significan de forma simbólica diferentes maneras de entender la masculinidad y la feminidad, siempre en función de claves como la oposición entre virtud y pecado.

b) Normatividad: ahora bien, el significado de un símbolo concreto es variable, de manera que son necesarias normas que regulen las interpretaciones correctas -en nuestro caso éticas-, de los símbolos. En el Corbacho, este marco normativo viene dado por una serie de ejes conceptuales: amor a Dios/amor al mundo, salvación/condena, virtud/vicio, razón/pasiones. Así, la forma de interpretar los diferentes símbolos y representaciones que hemos visto dependen de este bagaje conceptual, de manera que la Virgen y Jesucristo se asocian con el amor a Dios, la salvación y la virtud, mientras que Adán y Eva se identifican con el pecado y la condena. Ahora bien, aunque una mujer específica como María tenga un valor positivo, ya que su ejemplo conduce a la salvación; la mujer, en términos generales, se asocia al mundo, como las riquezas y las posesiones:

Por ende, amigo, si considerases cómo sólo amar a Dios es sabieza, virtud e proeza, donde mucho e infinito bien espera el que le ama de coraçón, e que e amar cosas mundanales -riquezas, mugeres e estados- es loco e vano amor e viçio contra virtud, por el qual tantos dapnos, como susodiche he, se siguen e provienen (GERLI, 2011: 201).

Ahora bien, el discurso del Arcipreste se sitúa en un conflicto intelectual, que podemos entender como una suerte de crisis cultural en torno a la interpretación de las representaciones de género. Es decir, la querella de las mujeres es, en buena medida, una discusión en torno a las normas que regulan no la interpretación de 
las representaciones y símbolos de lo masculino y femenino, sino de las propias normas sociales que regulan el comportamiento de los sexos. Así, autores como Juan Rodríguez de Padrón o Álvaro de Luna ponen en duda la mayor culpa que tradicionalmente tendría Eva en relación con la expulsión del Paraíso, por ejemplo (VARGAS, 2013: 263-288; FuENTES, 2009). Debemos entender esto en el contexto de un pensamiento (el del amor cortés) que representa a la mujer como un modelo y un incentivo para la virtud. De esta forma, autores como Juan Rodríguez de Padrón o Álvaro de Luna usan a la mujer como símbolo de virtud y honor, un uso totalmente contrario al del Arcipreste, quien asocia el concepto de mujer con el pecado y el mundo.

c) Instituciones y organización social: el género puede llevar a una diferenciación en relación con actividades y posiciones sociales que se les suponen a hombres y mujeres, en instituciones con el parentesco. La más importante en el Corbacho es el matrimonio, que regula la sexualidad lícita, pero también está condicionado por elementos como la edad, de forma que el único matrimonio realmente lícito es entre dos jóvenes, ya que los otros resultarían perjudiciales tanto para los contrayentes como para la sociedad (GERLI, 2011: 225-229). El matrimonio es central como elemento regulador de las relaciones de género, y su ausencia afectaría además a otras realidades sociales e institucionales, para Martínez de Toledo, de forma que las relaciones sexuales fuera del matrimonio institución consecuencias nefastas. Así, al describir los resultados del «amor desordenado», es decir, del sexo ilícito, el Arcipreste afirma que este trae graves consecuencias para las riquezas, el estatus social, la reputación de los amantes o incluso para el gobierno de la ciudad. ${ }^{13}$ De nuevo, el lugar central que tiene el matrimonio en el discurso del Arcipreste a la hora de regular lo social debe verse en relación a su crítica del ambiente cultural cortés, en el que se da una suerte de exaltación de las relaciones adúlteras, aunque sea a nivel imaginario (MAÑERO, 1997: 416-418).

A mayores, a la hora de expresar las relaciones de poder de hombres sobre mujeres, el Arcipreste recurre a un lenguaje propio de instituciones feudovasalláticas, de las relaciones maestro-aprendiz y en términos generales, de situaciones en las que existe una parte bajo el poder de otra:

Paren mientes a este ensiemplo muchos, empero más las mugeres, que saben las cargas que han de soportar quando se dieren a varón por amigança, amores o casamiento; que su libertad al que se dieron sometieron, aquella poca o mucha que tenían [...]. Eso mesmo del vasallo contra el señor e el servidor conta su maestro, el súbdicto contra su subjugante, el menor contra su mayor, que como dize el sabio: «A aquellos que de nos son más poderosos, ser eguales non podemos» (GERLI, 2011: 165).

Aunque es relativamente habitual que se emplee el lenguaje de género como una manera de expresar poder en otros ámbitos sociales (MEYEROWITZ, 2008: 13481351), aquí se hace lo contrario, es decir, usar otro tipo de relaciones en la que existe dominio como forma de expresar el poder del hombre sobre la mujer. ${ }^{14}$

d) Cuerpo: a la hora de articular las diferencias sociales y culturales entre hombres y mujeres, es decir, el género, los discursos medievales buscan legitimar

13 En este sentido, el Corbacho tiene un marcado carácter urbano, percibiendo el amor desordenado como una amenaza para el orden político de la ciudad (RANK, 1997: 160-163).

14 Véase también VéLEZ-SAínz (2013: 150). 
dichas diferencias en ámbitos que no son propiamente sociales. Uno de esos ámbitos sería el del cuerpo, o el de la relación entre el cuerpo y el alma. De este modo, los significados atribuidos a las diferencias sexuales a nivel físico, se vuelven una parte del género, ya que estos significados se basan en tradiciones culturales específicas (Sсотт, 1999). En el caso del Corbacho, se recurre, en buena medida, a las tradiciones médicas. El tratamiento que se hace del comportamiento de los hombres como derivado de una serie de condiciones fisiológicas está fundamentado en la idea de que es más complejo entender el comportamiento del varón:

E por quanto comúnmente los ombres non son comprhendidos como las mugeres so reglas generasles -esto por el seso mayor e más juizio que alcançan- conviene, pues, particularmente fablar de cada uno segund su cualidad [...]. E aunque tal es mesmo de las mugeres, pero generalmente ellas tienen otras condiçiones que los ombres [...] (GERLI, 2011: 204).

Con estas ideas, el Arcipreste está recurriendo a toda una serie de tradiciones medievales que relacionan astrología, fisionomía y comportamiento, y que sirven a menudo para justificar las diferencias sociales y culturales entre hombres y mujeres. Al hombre se lo tiende a presentar como más noble, trabajador, impulsivo; mientras que la mujer, más fría, tendría menos inclinación por la actividad física (CADDEN, 1993: 187-188). Esta tendencia a identificar lo activo con lo masculino y lo pasivo con lo femenino también está presente en las descripciones que proporciona Martínez de Toledo de los hombres flemáticos, que, al estar identificados con el frío y la humedad, podrían considerarse como hombres hasta cierto punto feminizados, con poca tendencia a la actividad. Los flemáticos, por ejemplo, son «tibios», «dormidores», «más flojos que la madexa», así como «ligeros de seso» (GERLI, 2011: 208). De hecho, el Arcipreste es explícito al tratar la actitud cobarde de los flemáticos: «Desque ella vee que está templando como azogado e más muerto que bivo, e vee que aunque quedase, que non quedava con ella ombre sinón muger, dize ella; "Pues muger por muger, non he menester aquí otra mujer"»(GERLI, 2011: 224). Es decir, el Arcipreste identifica el comportamiento poco activo y valeroso del hombre flemático con lo femenino. Así, las características fisiológicas de hombres y mujeres resultan determinantes como estrategia para justificar las diferencias sociales, no sólo entre hombres y mujeres, sino incluso entre las diferentes masculinidades, de forma que las masculinidades más femeninas, como el caso de los flemáticos, son también masculinidades subordinadas.

El género opera en el Corbacho, como construcción social entorno a las diferencias de sexo, a través una serie de elementos discursivos y representaciones, que funcionan en una serie de contextos determinados. Cuestiones como los símbolos y la normatividad a la hora de interpretar estos pueden ser entendidas dentro del debate de la querella de las mujeres, mientras que la defensa del matrimonio como una de las instituciones fundamentales a la hora de regular las relaciones de género, especialmente las relaciones sexuales, resulta ser una suerte de crítica a la presencia de relaciones adúlteras en los discursos del amor cortés. Finalmente, el cuerpo, a través de una serie de tradiciones médicas medievales, funciona como justificación de las diferencias sexuales. También se construyen, a través del cuerpo, una legitimación de las diferencias entre distintas 
masculinidades, que veremos a continuación.

\section{MASCULINIDADES EN EL CORBACHO}

El programa de reforma moral y social del Arcipreste está orientado, como ya se ha dicho, hacia un cambio en las relaciones de género. $Y$ el género, en cuanto concepto analítico, lidia tanto con los hombres como con las mujeres (ZANCARINIFOURNEL, 2010: 216), preguntándose por la atribución de diferentes roles y significaciones a cada uno de los sexos. Asimismo, la situación social de cada uno de los sexos no es totalmente homogénea, sino que existe variedad dentro de lo femenino y lo masculino. No existe una única masculinidad para todos los varones, sino más bien diferentes formas de ser hombres. En el Arcipreste de Talavera se representan diversas masculinidades, algunas valoradas positivamente, como los hombres sanguíneos y coléricos, y otras valoradas negativamente, como el amante cortés; casi siempre en relación con las claves morales que hemos visto.

Entre estas distintas masculinidades, que se articulan como categorías o identidades a las que se asocian distintos roles, se proyectan también jerarquías y relaciones de poder. Así, se configuran masculinidades hegemónicas, que identificarían a los varones que ejercen cierto poder o control sobre otros, que se agruparían como masculinidades subordinadas (CONNELL y MESSERSCHMIDT, 2005: 846-847). En el Corbacho, estas jerarquías son dependientes, principalmente, de las claves morales que hemos anticipado: las masculinidades hegemónicas se configuran en relación con el amor a Dios y a la virtud, a la capacidad de la razón para dominar al cuerpo; mientras que las masculinidades subordinadas se relacionan con el pecado y la incapacidad de hacer frente a las tentaciones, es decir, al dominio de los apetitos sobre el alma racional. ${ }^{15}$

Las masculinidades hegemónicas se caracterizan entonces por situarse en la parte superior de una jerarquía. En el caso del Corbacho, como decíamos, la jerarquía viene determinada por el eje entre amor a Dios y amor mundano, de forma que los valores y comportamientos asociados al amor a Dios suponen una mayor posición jerárquica en el discurso del Arcipreste de Talavera.

En el texto, la parte en la que se trata la masculinidad con mayor extensión es la relativa a los temperamentos, de forma que se asocia el comportamiento más admirable con dos categorías médicas: los sanguíneos y los coléricos, que serían «las complisiones mejores e de mayor excelencia» El caso más claro es el de los sanguíneos, que se asocian especialmente con virtudes especialmente relevantes como la honestidad, la justicia, la misericordia o la piedad, y especialmente, con la mesura (GERLI, 2011: 207-208), una cualidad central en la adquisición de cualquier virtud. Cabe destacar, además, que, en la tradición galénica, el hombre sanguíneo

15 En relación con la pérdida de racionalidad entre los pecadores en el Corbacho, veánse GonZÁLezCASASNOVAS (1991) y KÜPPER (2008). Véase también la discusión entorno a la locura y a las complexiones de los hombres en TREjo BARRIEnTOS (2016: 138-141), que destaca que «[1]a explicación elaborada por Martínez de Toledo tiene propósitos diferentes: él quiere señalar ventajas y desventajas para las mujeres, y como podemos derivar de la relación de las maneras del matrimonio, quiere dar a la mujer elementos para escoger a quién amar y con quién casarse; con ello intenta establecer un intento de balance con respecto a la evidente y reiterada condena de la mujer dirigida a los hombres en las primeras dos partes» (175). Aún así, el autor reconoce que no se puede establecer una equidad en las críticas que realiza el Arcipreste. 
poseía un temperamento apropiado para desempeñar actividades más altas en la jerarquía social. De un noble, de un prelado, o de un obispo se esperaba que manifestaran comportamientos propios del sanguíneo (CÁRDENAS, 1988: 480-481). También dentro de una categoría hegemónica aparecerían los coléricos, que, aunque tendrían ciertas inclinaciones perjudiciales -«son irados muy de rezio, sin temprança alguna»-, se nos dice que «aman justiçia e non todavía son buenos para la mandar, mejores para la executar». Asimismo, serían «muy curiosos e de grand seso, ardidos, sotiles, sabios, ingeniosos, movidos de ligero e feridores» (GERLI, 2011: 208-217).

Ahora bien, las predisposiciones de estos dos temperamentos pueden volverse negativas cuando son empleadas sin atender a la razón. Así, al construirse la masculinidad en relación a lo femenino, la degeneración de la masculinidad en el hombre sanguíneo y el hombre colérico se construye en conexión con las mujeres. El hombre sanguíneo resultaría perjudicial para las mujeres que se relacionan con él, debido a su falta de constancia y continuos enamoramientos, mientras que, el hombre colérico sería fácil de engañar por su amante, debido a su facilidad para la ira: «Por ende, las mugeres aman a estos mucho por vengar sus injurias» (GERLI, 2011: 212-217).

Con todo, el tipo de masculinidades que más presencia tienen en el Corbacho son las masculinidades que el Arcipreste de Talavera consideraría masculinidades que deben estar subordinadas. Se trataría de masculinidades que resultan perjudiciales moral y socialmente y que son por lo tanto criticables. Esto no quiere decir, claro, que alguna de las masculinidades que se critican no fuera vigente de forma hegemónica en otros discursos, como los cortesanos. De hecho, las críticas a la figura del amante cortesano, una masculinidad central en los discursos del amor cortés aparece en múltiples ocasiones a lo largo del Corbacho.

El amante cortés, como tipo de masculinidad, es criticado en múltiples ocasiones a lo largo de la obra, normalmente en los mismos términos (MAÑERO, 1997: 416-419). La crítica del Arcipreste se basa en pretender desvelar las verdaderas intenciones del pretendiente. La intención de los cortesanos, por mucho que halaguen, vayan a fiestas y prometan todo tipo de bienes a las damas, casi siempre es la gratificación sexual, lo que los sitúa, en el esquema del Arcipreste, del lado del amor mundano y, por tanto, como un tipo de masculinidad que debe rechazarse. Así, se nos presenta al amante cortés como un embaucador en varias ocasiones. Por ejemplo, en el capítulo XXVI de la primera parte, relativo al séptimo mandamiento, se afirma que van a galas y bailes con el único fin de «alcançar las que más aman e por con ellas desonestamente usar» (GERLI, 2011: 121). Pero donde más se desarrolla estas ideas sería en el capítulo dedicado a las capacidades para amar del hombre sanguíneo. En él se nos describe toda una serie de prácticas asociadas al amor cortés, que, para el Arcipreste, por el contenido pecaminoso que tienen, deberían ser marginalizadas: legitimar, escogiendo selectivamente pasajes de las escrituras, la fornicación; su incapaz de ser firmes en sus relaciones, causando la pérdida de honra en muchas mujeres; o hacer a damas escaparse de su familia con ellas con falsas promesas (GERLI, 2011: 212-215). Otra forma de subordinar al amante cortés es mediante la burla. En este sentido, la descripción del flemático resulta ser una parodia de las virtudes que se le suponían al pretendiente en el amor cortés (WHITBOURN, 1970: 43-44). El Arcipreste pone en boca del hombre flemático lo siguiente: «Iré; non iré; sí iré. Sivo, verme han, mojarme he, me encontraré con la justicia e tomarme ha la espada (...) ensuziarme he de 
lodo los çapatos de alta grasa (...) ¡Guay, si me muerde algund perro en la pierna, o si me dan en la cabeça alguna pedrada [...]?» (GERLI, 2011: 222). Se nos describe al amante como un hombre cobarde, amedrentado ante cualquier peligro potencial, en comparación con el valor que se le presupone al cortesano. En definitiva, el Arcipreste sigue una serie de estrategias que presentan al amante cortés como un modelo que no se debe seguir en la construcción de la masculinidad.

Otra masculinidad presente en el Arcipreste de Talavera, de una manera mucho más marginal, es la de los «bigardos», que se conceptualizan como hipócritas, herejes y sodomitas; lo que serviría para construir un otro marginado (BROWN, 1999: 84-86) que permitiría configurar las masculinidades más apropiadas. En este sentido, los «bigardos» se presentan como hombres con un comportamiento femenino:

E destos bigardos algunos dellos son en dos maneras: ay unos que se dan al acto varonil, desean compaña de omes por su vil acto, como ombres, con los tales cometer. Ay otros destos que son como mugeres en sus fechos e como fembrezillas en sus desordenados apetitos, e desean a los omes con mayor ardor que las mugeres desean a los ombres. ¡Fuego, fuego en ellos! E déstos non digo nada, por quanto sería grand fealdad dezir sus abominables obras de sodeníticos fechos [...] (GERLI, 2011: 259).

Mientras que la figura del amante cortés es criticable, esta aparece directamente excluida de la sociedad; ahora bien, enjuiciada mediante las claves de las que venimos hablando. Así, se los califica como «malvados brutos e animales de juizio, seso, razón e entendimiento carecientes», relacionando así este tipo de comportamientos con la ausencia de razón, el sometimiento al cuerpo y, por supuesto, con la condena.

Partiendo de una serie de elementos de las tradiciones médicas medievales, en especial en relación con la teoría de los humores, y siempre teniendo en cuenta la oposición entre amor a Dios y amor al mundo y entre la virtud y el pecado, el Arcipreste de Talavera construye una suerte de clasificación de las masculinidades. De los sanguíneos y los coléricos se destacan elementos como la honestidad, la justicia, la piedad y la misericordia, algo que los convertiría en una suerte de buenos varones, mientras que los flemáticos y melancólicos están aquejados de vicios como la envidia o la cobardía. Los sanguíneos y coléricos se nos aparecen, entonces, como masculinidades hegemónicas, mientras que los flemáticos y melancólicos son masculinidades no deseables, según la jerarquía que se desliza en el discurso de Martínez de Toledo, aunque cabe destacar que las diferencias no son totalmente rígidas. Con todo, el Arcipreste usa estas categorías para criticar el modelo de lo masculino que considera nocivo: el del amante cortesano. Diferentes prácticas propias de la corte se presentan como pecaminosos o incluso blasfemas. A todo esto, habría que añadir la total exclusión de masculinidades como los «bigardos» o los «sodomitas».

\section{FEMINIDADES EN EL CORBACHO}

En el Corbacho también se refleja una serie de características relativas a la cultura femenina, es decir, a los aspectos de expresión propiamente femeninos, que permiten la formación de comunicación y perpetuación de saberes y actitudes sobre la vida. Nos referimos aquí a la construcción de elementos relativos a la 
feminidad, es decir, a las actividades, espacios y roles específicos de las mujeres, que están diferenciados de los hombres (FARGE, 1991: 88). Se podría apuntar que el Corbacho, al ser un texto en el que se resalta una preocupación por la construcción de las relaciones de género, necesita pensar una serie de aspectos relativos a esta cultura, ya que esta concierne a toda la organización social. Aunque los aspectos que se destacan en el texto de la cultura femenina son principalmente negativos, también aparecen otros elementos que pueden servir para reconstruir cómo se configuran feminidades positivas, es decir, moralmente aceptables, en las relaciones de género propuestas por el Arcipreste de Talavera. Hay feminidades positivas y negativas en la interpretación de la cultura femenina que proporciona Martínez de Toledo, que se expresan en relación con la cultura material, con las formas de expresarse y, especialmente, con los comportamientos -virtuosos y viciosos-.

Como en el caso de las masculinidades, las feminidades se construyen como ideales, como modelos de comportamiento, no necesariamente como descripciones empíricas de la realidad (ScotT, 1999: 205-206). En la obra del Arcipreste se presenta, especialmente en el caso de las mujeres, una oposición entre dos polos, uno positivo y loable, es decir, una forma de ser mujer que sería socialmente aceptable; mientras que otra, la más presente en el texto, sería perjudicial tanto para las mujeres a las que se atribuyen comportamientos cuestionables, como para los hombres que tienen relaciones con ellas. El proceder del Arcipreste, a la hora de articular ambas construcciones, consiste en una «estética de los contrarios» (NePAulsingH, 1980: 329-330), un método retórico medieval por el cual se criticaría un objeto con el fin de alabar a su contrario. Así, el Arcipreste afirma que «maldezir del malo, loança es del bueno» (GERLI, 2011: 65). En este sentido, todas las críticas hacia las mujeres pecadoras o viciosas suponen el reconocimiento de una feminidad moralmente correcta, algo que también se transluce en las ocasionales referencias a la Virgen María, como intercesora por las almas. Como vemos, la relación entre feminidades positivas o feminidades negativas se articula en los mismos términos abstractos que las masculinidades -y en general todas las valoraciones morales del Arcipreste-, aunque cambia en sus contenidos concretos.

Un buen resumen de los valores que el Arcipreste considera apropiados para una mujer aparece a final del capítulo VII de la primera parte, después de criticar el comportamiento de los hombres sanguíneos hacia las mujeres. El Arcipreste da una serie de consejos al género femenino para evitar los problemas derivados de hacer caso a este tipo de hombres:

Por ende, créame la que quisiere, e ame a Dios primeramente. Ame a su breve tiempo, ese poco que ha de durar, que le non despienda en locuras, pues ha de dar cuenta dél, e aun de toda palabra oçiosa. Ame a su fama e honra. Ame a sus parientes do viene. Ame a sí más que non a otro, e non crea de ligero nin buelva sus ojos a son de pandero. Sea contenta con honestidad e buen renombre e buena fama, comiendo e paçiendo las yervas, e con sólo pan e agua, estando entre dos paredes; que más vale a ella mill vezes que non ufanías e locuras e pompas e vanaglorias, seyendo deshonradas e vituperadas, e mal traídas locamente amando (GERLI, 2011: 216).

En este pasaje se ven claramente algunos de los aspectos centrales de las ideas del Arcipreste sobre la virtud en la mujer. Estos se centran en el amor a Dios y en 
la no consecución de los impulsos - de ahí la idea de no gastar el tiempo en locuras o no creer con facilidad las promesas de los hombres-. Pero también se translucen otros aspectos interesantes. Así, la referencia a las palabras ociosas puede ser contrastado con la representación constante de la mujer viciosa, caracterizada por un habla excesiva. Así, se puede plantear que la relación del habla con la mujer, para el Arcipreste y su grupo social, debe ser una de contención. El sexo femenino debe tener cuidado con su habla. Asimismo, la apelación a la honestidad y a la buena fama coincide con las recomendaciones que se expresan tanto a hombres como mujeres en el capítulo viII de la primera parte, junto con la continencia (GERLI, 2011: 80-81). Honestidad, castidad y buena fama aparecen para el Arcipreste relacionadas con el ejercicio de una sexualidad ordenada, de forma que las relaciones ilícitas llevarían a una pérdida de reputación y posición social. También destaca la importancia del parentesco en una cultura femenina apropiada, ya que se sitúa a menudo a la mujer en una posición subordinada a su padre o hermano. Así, en el capítulo II de la primera parte, se afirma la posibilidad de que la mujer que tiene relaciones ilícitas sea asesinada por el hombre a cuyo cargo están: «[...] fazes perder la cuitada que tu loco amor cree [...] que la mata su marido por justicia, o súbitamente a desora o con ponçoñas; o el padre a la fija, o el hermano a la hermana, o el primo a la prima [...]». Se presenta aquí un caso extremo de la situación social en la que coloca el Arcipreste a la mujer, en subordinación a una autoridad masculina.

Finalmente, en el pasaje que citamos al principio, destacan aspectos relativos a la cultura material femenina. La alusión al emparedamiento, una forma de vida ascética femenina en la Baja Edad Media, podría ser una exageración de los espacios domésticos que el Arcipreste consideraría adecuados para el género femenino. Situémonos, en este sentido, en un contexto en el que está surgiendo una progresiva domesticidad para las mujeres, en la que la casa es un ámbito femenino, y está emergiendo una piedad, femenina también, caracterizada también por su domesticidad (BenNETT y KARRAS, 2013: 8-9). Así, cabe destacar también que en otro pasaje dedicado a la cantidad de bienes materiales que poseen las mujeres, el Arcipreste afirma: «Todas estas cosas fallaréis en los cofres de las mugeres: Horas de Santa María, siete salmos, estorias de santos, salterio en romançe, ¡nin verle del ojo!» (GERLI, 2011: 159). Esta crítica, la ausencia de textos devocionales entre la cultura material femenina, o al menos entre los objetos de las mujeres pecadoras, apunta a cuál es la actividad que el Arcipreste aconseja, o quiere imponer, al género femenino en su programa de reforma moral, centrado en el amor a Dios.

Así, el mundo femenino a alcanzar no se localiza únicamente en relación con la sexualidad, sino también en relación con otra serie de aspectos en los que se tienen en cuenta, a grandes rasgos, las formas de expresarse de las mujeres -el habla-, la relación con los hombres, la importancia de virtudes como la continencia y la honestidad como sustentadoras de la reputación y la posición social, o la relevancia de la domesticidad y la devoción privada. En este sentido, el Arcipreste hace una interpretación de cómo debe ser la cultura femenina en las relaciones de género que él propone, una interpretación basada, en última instancia, en la distinción entre amor mundano y amor a Dios -clara, por ejemplo, en la oposición de material devocional a todo tipo de adornos u otros bienes que cabría calificar como mundanos-, pero también una interpretación que entronca con una tradición eclesiástica en la concepción de la mujer que se puede remontar 
a los primeros siglos del cristianismo.

Con todo, la visión de la cultura femenina en el Arcipreste de Talavera tiene un tono fundamentalmente negativo, derivado, como decíamos, de sus propósitos didácticos y morales y de sus estrategias retóricas. Aunque ya se han tratado con anterioridad las representaciones negativas de las mujeres en el texto, el discurso de Martínez de Toledo también refleja unos modos de expresarse, una cultura material, y unos comportamientos propios de las feminidades medievales. Ahora bien, no cabe entender el Corbacho como una descripción realista de la realidad de las mujeres del siglo $\mathrm{XV}$, sino, más bien, como una construcción híbrida entre la realidad y el mensaje ejemplarizante (BROwN, 1999: 77-80) que quiere transmitir el Arcipreste de Talavera.

En general, podemos englobar las construcciones que hace el Arcipreste de Talavera de la cultura femenina en un sentido negativo, es decir, la construcción de feminidades no deseables, en torno a varios elementos:

a) el pecado y el vicio: el pecado tiene una importante presencia en el comportamiento de las mujeres que nos presenta Martínez de Toledo. La feminidad negativa se caracterizaría por una constelación de pecados entre los que sobresalen pecados capitales como la avaricia, la envidia o la soberbia, que sirven para englobar todo un conjunto de comportamientos condenables.

b) el habla: si bien la caracterización del habla excesiva cae en varios pecados -el largo monólogo sobre el huevo y la gallina, en el que una mujer descontroladamente por la pérdida de un huevo y una gallina pertenecería al ámbito de la avaricia-, existe también un énfasis en el carácter "maldiziente» de la mujer, que se expresa en constantes exclamaciones blasfemas puestas en bocas de mujeres.

c) el engaño como forma de relación con los hombres, que se expresa a múltiples niveles: el uso continuo del ornato, el murmullo, la falta de constancia, la desobediencia, el cotilleo...

d) una cultura material basada en lo mundano, dónde entra principalmente el adorno, pero también las ropas que se describen como forma de reputación entre mujeres en varias ocasiones. ${ }^{16}$

Estos elementos, además, parecen funcionar como una suerte de parodia de las damas del amor cortés. Mientras que la mujer en este tipo de composiciones poéticas aparece como una idealización virtuosa, Martínez de Toledo la plaga de vicios; y frente a la belleza de aquellas, las mujeres que pueblan el texto del Arcipreste sólo son hermosas aparentemente, debido a un uso pecaminoso de ropas y adornos.

Por otra parte, frente a unas mujeres con las que el hombre debe evitar relacionarse lo máximo posible, también aparecen tipos femeninos marginales, como puedan ser las alcahuetas, prostitutas avejentadas (WHITBOURN, 1970: 41-43). Estas se identifican con la hechicería, una actividad femenina -que tiene su polo masculino en el caso de los «bigardos», totalmente condenable, y que se articula en oposición al amor divino:

viejas matronas, malditas de Dios y de sus santos, enemigas de la Virgen Santa María; que desde que ellas no son para el mundo ni las quieren, en tanto que a

16 Todos estos elementos se insertan además, en un texto en el que la descripción de lo grotesco tiene un lugar central, como forma de intentar mitigar las tentaciones que pudieran sufrir los varones. Sobre lo grotesco en el Corbacho veánse GOLDBERG (1978-1979) y SANMARTín BASTIDA (2003b). 
sí mismas en los tiempos pasados destruyeron y difamaron y perpetualmente se condenaron a las penas infernales por los enormes pecados que cometieron en este acto, y así fenecieron y continuaron a ser de tal edad que el mundo las aborrece y ya ninguno ni las desea ni las quiere; y entonces toman oficio de alcahuetas, hechiceras y adivinadoras, por hacer perder otras como ellas [...]. Hacen a los casados dejar a sus mujeres e ir a las extrañas; eso mismo la mujer, dejando a su marido, irse con otro [...]. Así van las bestias de hombres y mujeres a estas viejas por hechizos como a pendón herido (GERLI, 2011: 197).

Este tipo femenino se percibe como tremendamente perjudicial a varios niveles: su enemistad con Dios, los santos y la Virgen, su condena, y el peligro que suponen para los matrimonios, institución fundamental en las relaciones de género y la regulación de la sexualidad. En este sentido, destaca el calificativo de «bestias» para los hombres y mujeres que tratan con las brujas, un término que el Arcipreste usa para expresar los comportamientos que no se ajustan a la razón. En este sentido, la condena de las alcahuetas, y la construcción de una cultura femenina en negativo, se da con relación a las claves interpretativas que el Arcipreste vendría usando durante todo el texto: los ejes entre amor mundano y amor a Dios, entre emociones, y razón y entre lo corporal y lo espiritual.

\section{CONCLUSIONES}

El núcleo de este trabajo ha sido el concepto de género, en línea con la definición de Joan Scott, que, en relación con otros conceptos como cultura femenina, ideales de feminidad o masculinidades hegemónicas y subordinadas, aportan un aparato conceptual y teórico apropiado para estudiar la obra, aunque no es, desde luego, el único posible. Así, se ha intentado mostrar las posibles utilidades del bagaje teórico e historiográfico de la historia de género a la hora de estudiar un texto del siglo $\mathrm{XV}$ en relación con la construcción de masculinidades y feminidades y la articulación de las diferencias entre los sexos a través del discurso de Martínez de Toledo.

En el Corbacho se configura un discurso de género basado principalmente en la oposición entre amor a Dios y amor al mundo. Hemos visto cómo a través del concepto de género se puede comprender un conjunto de elementos del texto, que van desde el uso de figuras femeninas como la virgen María, Betsabé o Eva para representar lo femenino, a la construcción de una jerarquía de masculinidades basada en las concepciones médicas sobre los humores y el temperamento; pasando por la centralidad del matrimonio como institución reguladora de las relaciones sexuales o el recurso a la anatomía y a las tradiciones médicas medievales como justificación de las diferencias sexuales.

En términos generales, el discurso del Arcipreste ataca principalmente a los discursos y prácticas relacionados con el amor cortés, de ahí que, en la construcción de jerarquías entre diferentes tipos de masculinidad, el amante cortesano sea una figura a la que se da un valor subordinado. De la misma manera, los ideales negativos de feminidad parecen parodiar discursos y prácticas cortesanas. Estos elementos responden al contexto cultural del Arcipreste, en el que el amor cortés tendría una fuerte presencia, de forma que el Corbacho, y la querella de las mujeres, pueden verse como las manifestaciones de un conflicto cultural en torno 
a la definición de las normas de género.

\section{REFERENCIAS}

ARCHER, R. (2012): «La misoginia como 'remedium amoris'», Bulletin of Hispanic Studies, 89 (3): 237-254

ARCHER, R. (2005): The problem of women in late medieval hispanic literature, Tamesis, Woodbridge.

BENNETT, J.M.; KARRAS, R.M. (2013): «Women, gender and medieval historians», en J.M. BENNETT y R.M. KARRAS (eds.), The Oxford handbook of women and gender in medieval Europe, Oxford University Press, Oxford: 1-17.

Bermejo CABrero, J.L., (1976): «La formación jurídica del Arcipreste de Talavera», Revista de filología española, 57: 111-125.

BLOCH, R.H. (1991): Medieval misoginy and the invention of western romantic love, The University of Chicago Press, Chicago \& London.

Bock, G. (1991): «La historia de las mujeres y la historia del género: aspectos de un debate internacional», Historia social, 9: 55-77.

Bolufer, M.; CABrÉ, M. (2015): «La querelle des femmes en Espagne: bilan sur l'histoire d'un débat (1400-1800)», en M. E. Hennau y R. V. Kulessa (eds.), Revisiter la querelle des femmes. Discours sur l'égalité/inégalité des femmes et des hommes à l'échelle européenne, Presses universitaires de Saint-Etienne, SaintEtienne: 31-45.

BoyDSTON, J. (2008): «Gender as a question of historical analysis», Gender E History, 20 (3): 558-583.

BROWN, C. (1999): «Queer Representation in the Arçipreste de Talavera, or the Maldezir de mugeres is a drag», en J. Blackmore y G.S. HutCHESON (eds.), Queer Iberia. Sexualities, cultures, and crossings from the Middle Ages to the Renaissance, Duke University Press, Durham \& London: 73-103.

Cadden, J. (1993): The meanings of sex difference in the Middle Ages: medicine, science and culture, Cambridge University Press, Cambridge.

CANNING, K. (2006): Gender history in practice. Historical perspectives on bodies, class and citizenship, Cornell University Press, Ithaca \& London.

CÁrdenas, A.J. (1988): "The "conplisiones de los onbres" of the Arcipreste de Talavera and the male lovers of the Celestina», Hispania, 17 (3): 479-491.

Chartier, R. (1999): El mundo como representación. Historia cultural: entre práctica representación, Gedisa, Barcelona.

Connell, R.W.; MEsserschmidt, J.W. (2005): «Hegemonic masculinity: rethinking the concept», Gender \& Society, 19 (6): 829-859.

DiFRANCO, R. (1982): «Rethoric and some narrative techniques in the Corbacho of Alfonso Martínez de Toledo», Kentucky Romance Quarterly, 29 (2): 135-142.

ElliotT, D. (2008): «The three ages of Joan Scott», American Historical Review, 113 (5): 1390-1403.

FARGE, A. (1991): «Historia de las mujeres. Cultura y poder de las mujeres: ensayo de historiografía», Historia social, 9: 79-102.

Fuentes PÉrez, M.J. (2009): "Voces profemeninas en la querella de las mujeres: Álvaro de Luna y El libro de las claras y virtuosas mujeres», en C. SEGuRA 
(coord.), La Querella de las mujeres, vol. I, Análisis de textos, A. C. Almudayna, Madrid: 105-129.

GerLi, E.M. (1975): «"Ars Praecandi” and the structure of "Arcipreste de Talavera”, part I», Hispania, 58 (3): 430-441.

GerLI, E.M. (1978): «Boccaccio and Capellanus: tradition and innovation in "Arcipreste de Talavera"», Revista de estudios hispánicos, 12: 244-274.

GERLI, E.M. (1981), «La religión del amor y el antifeminismo en las letras castellanas del siglo XV», Hispanic Review, 49 (1): 65-86.

GerLI, E.M. ed. (2011): Arcipreste de Talavera o Corbacho/Alfonso Martínez de Toledo, Cátedra, Madrid.

GILES, R. (2008): «Depluming the author: the Corbacho and the crow of myth and fable», Bulletin of Hispanic Studies, 85: 625-637.

GoldBerG, H. (1978-1979): «The several faces of ugliness in medieval castilian literature», La Corónica: spanish medieval language and literature journal and newsletter, 7: 80-92

GonzÁlez-CASASNOVAS, R.J. (1991): «Rethorical strategies in the Corbacho, part III: from scholastic logic to homiletic example», La Corónica: spanish medieval language and literature journal and newsletter, 20 (1): 40-59.

Hernández SANDOICA, E. (2004): Tendencias historiográficas actuales. Escribir historia hoy, Akal, Madrid.

JEANNE, C. (2008): «La France: une délicate appropiation du genre», Genre $\mathcal{E}$ Histoire, 3.

Kelly, J. (1982): «Early feminist theory and the "Querelle des femmes", 14001789», Signs, 8 (1): 4-28.

KÜPPER, J. (2008): "Perception, cognition and volition in the "Arcipreste de Talavera" », en S. G. Nichols, A. Kablitz, y A. CAlHoun (eds.), Rethinking the medieval senses. Heritage, fascinations, frames, John Hopkins University Press, Baltimore: 119-153.

LE Goff, J. (1974): «Les mentalités: une histoire ambiguë», en J. LE Goff y P. NorA (dirs.), Faire l'histoire, vol. 3: nouveaux objets, Gallimard, 1974: 76-94.

MAÑERO, S. (1992): «El Arcipreste de Talavera: el público cortesano como elemento configurador», en R. Beltrán, J. L. CAnet y J. L. Sirera (eds.), Historias y ficciones: Coloquio sobre la literatura del Siglo XV. Actas del Coloquio Internacional organizado en el Departamento de Filología Española de la Universitat de Valencia, Departament de Filologia Espanyola, Valencia: 131-140.

MAÑERo, S. (1997): El Arcipreste de Talavera de Alfonso Martínez de Toledo, Instituto Provincial de Investigaciones y Estudios Toledanos, Toledo.

Martin, H. (1996): Mentalités médiévales: XIe-XVe siècle, Presses Universitaires de France, París, 1996.

Meyerowitz, J. (2008): "A History of "Gender"», American Historical Review, 113 (5): 1346-1356.

Morant, I. (2000): «Historia de las mujeres e historia: innovaciones y confrontaciones», en C. BArros (ed.), Historia a Debate, t. III, Problemas de Historiografía. Actas del II Congreso Internacional "Historia a Debate", celebrado del 14 al 18 de Julio de 1999 en Santiago de Compostela, Historia a Debate, Vedra: 294-295.

NePAulsingh, C. (1980): «Talavera's Imagery and the structure of the Corbacho», Revista Canadiense de Estudios Hispánicos, 4 (3): 329-349.

RANK, J.R. (1997): «Urban writing in the fifteenth century: on whose authority?», 
en D.J. Kagay y J.T. SnOw (eds.): Medieval Iberia: essays on the History and Literature of Medieval Spain, Peter Lang, New York.

Ríos DE LA LLAVE, R. (2018): “"No hay que tolerar a aquello que con boca de perro intentan hablar mal de las mujeres": Alonso de Cartagena, la cuarta cuestión del Duodenario y la Querella de las Mujeres», Medievalismo, 28: 203-233.

Rivera Garretas, M.M. (1996): «La querella de las mujeres: una interpretación desde la diferencia sexual», Política y cultura, 6: 25-39.

SAMPEDRO, R. (2018): «La querella de las mujeres en Castilla (siglo xv) y su relación con la historia de las mujeres y la historia de género», Historiografías, revista de historia y teoría, 16: 36-56.

SANMARTín BASTIDA, R. (2003a): Teatralidad y textualidad en el Arcipreste de Talavera, Department of Hispanic Studies, Londres.

SANMARTín BASTIDA, R. (2003b): «El Corbacho o el arte de la representación en el Bajo Medievo», eHumanista: journal of Iberian Studies, 3: 19-29.

SANTANA-PÉREZ, J.M.; SANMARTín BARROS, I. (2020): «La historiografía actual desde 1989», Vínculos de historia, 9: 345-366.

Scotт, J. (1986): «Gender: a useful category for historical analysis», American Historical Review, 91 (5): 1053-1075.

Scotт, J. (1999): Gender and the Politics of History, Columbia University Press, New York.

SEIDENSPINNER-NúnEZ, D. (1997): “"¡Guay del que duerme solo!”: The discourse of antifeminism and the collapse of the narrator in Arcipreste de Talavera», Anclajes. Revista del Instituto de Análisis Semiótico del Discurso, 1 (1): 159-177.

SENRA, J.; PONS, A. (2005): La historia cultural. Autores, obras y lugares, Akal, Madrid.

SERRANO, F. (2012): «Del debate a la propaganda política mediante la querella de las mujeres en Juan Rodríguez de Padrón, Diego de Valera y Álvaro de Luna», Talia dixit: revista interdisciplinar de retórica e historiografía, 7: 97-115.

Serrano, F. (2016): “" iCommo denuestas las mugeres!" Telle satire de la femme, telle theorie de la misogyne dans la littérature de savoir d'origine orientale et dans 1'Arcipreste de Talavera ou Corbacho», Cahiers d'études hispaniques médiévales, 39 (1): $61-80$.

Solomon, M. (1997): The literature of misoginy in medieval Spain, Cambridge University Press, Cambridge.

TREjo BARRIENTOS, A. (2016): «El loco amor como enfermedad mental. Los cuatro humores en el Arcipreste de Talavera o Corbacho, de Alfonso Martínez de Toledo», Acta poética, 37 (1): 129-144.

VARgas Martínez, A. (2000): «Lo que está vivo puede llegarnos. Una lectura desde la diferencia sexual de los tratados escritos por hombres en favor de las mujeres (Corona de Castilla, siglo xv)», en M. Cabré, C. Caballero, M. BERTRÁn, A. VARGAS, y M. M Rivera, De dos en dos. Las prácticas de creación y recreación de la vida y la convivencia humanas, Horas y horas, Madrid: 81-102.

VARgAs MARTíneZ, A. (2013): «Sobre los discursos políticos a favor de las mujeres (El Triunfo de las donas de Juan Rodríguez de la Cámara)», Arenal: revista de historia de las mujeres, 20 (2): 263-288.

Vélez-SAÍnZ, J. (2006): «De cuervos y basiliscos: alegoría y corte en el "Triunfo de las donas" de Juan Rodríguez del Padrón», RILCE: Revista de filología hispánica, 22 (2): 259-273.

VÉlEZ-SAÍnZ, J. (2013): «De amor, de honor e de donas». Mujer e ideales corteses en la Castilla de Juan II (1406-1454), Editorial Complutense, Madrid. 
WeIsS, J. (2002): “"¿Qué demandamos de las mujeres?": Forming the Debate about Women in Late Medieval and Early Modern Spain (with a Baroque Response)», en T. S. FENSTER y C. A. LEES, (eds.), Gender in debate from the Early Middle Ages to the Renaissance, Palgrave, New York: 237-274.

West, C.; ZimmermanN, D.H. (1987): «Doing Gender», Gender E Society, 1 (2): 125151.

WhitBourn, C.J. (1970): The 'Arcipreste de Talavera' and the literature oflove, University of Hull Publications, Hull.

WiSE, D.O. (1980): «Reflections on Andreas Capellanus' De reprobatio amoris in Juan Ruiz, Alfonso Martínez, and Fernando Rojas», Hispania, 63 (3): 506-513.

ZANCARINI-FOURNEL, M. (2010): «Histoire des femmes, histoire du genre», en C. Delacroix, F. Dosse, P. García y N. Offenstadt (dirs.), Historiographies, I. Concepts et débats, Gallimard, París.

ZimMERMANN, M. (1999): "Querelle des femmes, querelles du livre», en D. DE Courcelles y C. VAl Julián (eds.), Des femmes et des livres. France et Espagnes, XIV-XVIIe siècle. Actes de la journée d'étude organisée para l'École nationale des chartes et l'École normale supérieure de Fontenay/Saint-Cloud (Paris, 20 avril 1998), École des chartes, Paris: 79-94. 
